\title{
Photoluminescence, thermally stimulated luminescence and electron paramagnetic resonance studies of $\mathrm{U}^{6+}$ doped $\mathrm{BaSO}_{4}$
}

\author{
M K BHIDE, T K SESHAGIRI*, SASHIKALA OJHA ${ }^{\dagger}$ and S V GODBOLE \\ Radiochemistry Division, ${ }^{\dagger}$ Radiation Safety Systems Division, Bhabha Atomic Research Centre, Mumbai 400085 , India
}

MS received 24 August 2012; revised 5 October 2012

\begin{abstract}
U}^{6+}$ doped $\mathrm{BaSO}_{4}$ samples were synthesized by precipitation route. PL, TL and EPR investigations of $\gamma$ and self $\alpha$ irradiated samples were carried out. PL spectra of these samples give structured broad band peaking around $518 \mathrm{~nm}$ with five vibronic bands centred around 498.4, 516.0, 533.7, 554.0 and $575 \cdot 1 \mathrm{~nm}$, respectively and the average frequency of symmetric stretching of $O=U=O$ in the ground electronic state was found to be $674 \mathrm{~cm}^{-1}$. Trap level spectroscopic studies of $\mathrm{U}$ doped $\mathrm{BaSO}_{4}$ give glow peaks at 411,488 and $512 \mathrm{~K}$, respectively and their spectral characteristics are typical of $\mathrm{UO}_{2}^{2+}$ emission. EPR studies of $\gamma$-irradiated $\mathrm{U}^{6+}: \mathrm{BaSO}_{4}$ sample have shown the presence of sulphoxy centred radicals like $\mathrm{SO}_{4}^{-}$and $\mathrm{SO}_{3}^{-}$in addition to $\mathrm{OH}^{\bullet}, \mathrm{O}_{3}^{-}$and $\mathrm{SH}^{2-}$. TSL peaks at 411 and $488 \mathrm{~K}$ were correlated with thermal destruction of $\mathrm{SO}_{4}^{-}$and $\mathrm{SO}_{3}^{-}$radicals.
\end{abstract}

Keywords. EPR; TSL; PL; $\mathrm{BaSO}_{4}$; uranium.

\section{Introduction}

Alkaline-earth sulphates with suitable dopants have played an important role in the development of thermoluminescent dosimeters (Vohra et al 1980; Shinde et al 1996) and offer a very fertile area for further studies to elucidate the thermally stimulated reactions resulting in luminescence. Actinide doped alkaline-earth sulphates are of special interest due to an array of defect centres that can be generated in these solids by self $\alpha$ and $\gamma$ irradiation effects. Also structure of defect centres, their recombination on thermal stimulation resulting in luminescence, as well as possibility of stabilizing actinides in different valence states make them attractive host materials. Trap level spectroscopic studies of $\mathrm{U}^{6+} / \mathrm{Pu}^{4+} / \mathrm{Am}^{3+}$ doped $\mathrm{CaSO}_{4} / \mathrm{SrSO}_{4}$ using thermally stimulated luminescence (TSL) and electron paramagnetic resonance (EPR) were carried out earlier in our laboratory (Dalvi et al 1984; Seshagiri et al 1988, 1989; Kumar et al 1988; Natarajan et al 1989). Among these actinide elements, ${ }^{238} \mathrm{U}$ due to its long-half life is not expected to give much of internal damage over a short period of time, whereas, in ${ }^{239} \mathrm{Pu} /{ }^{241} \mathrm{Am}$ doped sulphates self irradiation effects were evident after short storage period of 5-10 days, resulting in the formation of variety of sulphoxy radicals due to high specific activity $\left(1.6 \times 10^{5}\right.$-dpm and $7.8 \times 10^{6}$-dpm, respectively) of these elements (Weast 1984). Uranium under normal conditions stabilizes in hexavalent state, though $\mathrm{U}^{3+}$, $\mathrm{U}^{4+}$ and $\mathrm{U}^{5+}$ states are possible under reducing conditions (Schreiber and Blazs 1982; Schreiber et al 1982). Hexavalent uranium depending on the synthesis conditions, can

*Author for correspondence (giritks@gmail.com) have different molecular structure leading to $\mathrm{UO}_{4}^{2-}, \mathrm{UO}_{6}^{6-}$ or $\mathrm{UO}_{2}^{2+}$ species (E. 't Lam and Blasse 1980). In the present study, photoluminescence (PL), thermally stimulated luminescence (TSL) and electron paramagnetic resonance (EPR) investigations of freshly prepared and stored $\mathrm{BaSO}_{4}: \mathrm{U}^{6+}$ samples were carried out with a view to understand the nature of defects formed by self $/ \gamma$ irradiation and stabilization of uranium species under these conditions.

\section{Experimental}

$\mathrm{U}^{6+}: \mathrm{BaSO}_{4}(1 \mathrm{~mol} \%)$ samples were prepared by mixing equimolar $(0.5 \mathrm{M})$ quantities of $\mathrm{Ba}\left(\mathrm{NO}_{3}\right)_{2}$ and $\left(\mathrm{NH}_{4}\right)_{2} \mathrm{SO}_{4}$ in solution. Appropriate amounts of high purity uranium as uranyl nitrate was added to $\mathrm{Ba}\left(\mathrm{NO}_{3}\right)_{2}$ solution before precipitation. Precipitate obtained was washed with quartz double-distilled water for 5-6 times to remove excess of ammonia present, dried and annealed at $1024 \mathrm{~K}$ for $2 \mathrm{~h}$. XRD of annealed powders were recorded using STOE X-ray diffractometer. PL, TSL and EPR investigations of freshly prepared and stored (300 days) $\mathrm{BaSO}_{4}: \mathrm{U}^{6+}$ were carried out. PL characterization was carried out using Edinburgh CD-920 fluorescence spectrometer. TSL studies were carried out on a home-built unit coupled to a personal computer by recording spectra of self and $\gamma$ irradiated samples (dose in the range of 0.5-3 KGy). Trap parameters were calculated for $\mathrm{BaSO}_{4}: \mathrm{U}^{6+}$ (dose $\left.=1.5 \mathrm{kGy}\right)$ sample by recording their TSL at different heating rates, e.g. 3, 2, 1 and $0.5 \mathrm{~K} / \mathrm{s}$. EPR spectra were recorded with Bruker ESP -300, X-band spectrometer, EPR and TSL spectra were correlated for deciding the stability of defect centres and their role in TSL. 


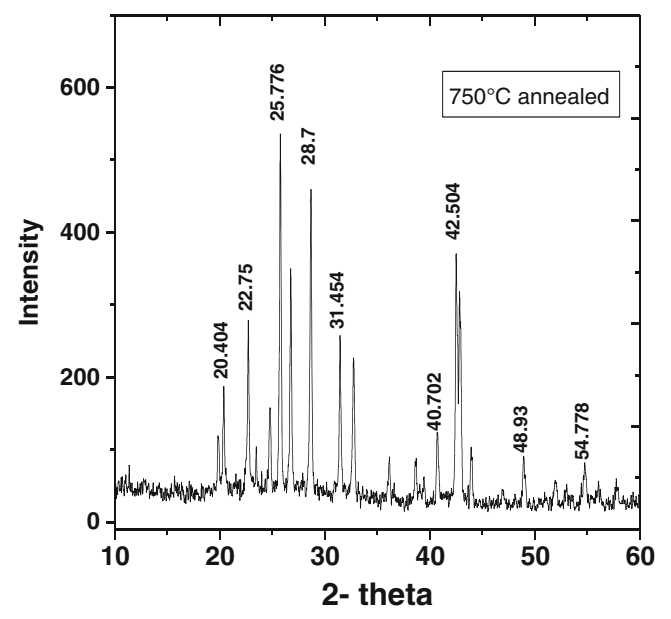

Figure 1. XRD pattern of $\mathrm{U}^{6+}: \mathrm{BaSO}_{4}$.

\section{Results and discussion}

\subsection{XRD and PL investigations}

XRD pattern of $1024 \mathrm{~K}$ annealed $\mathrm{U}^{6+}: \mathrm{BaSO}_{4}$ are given in figure 1. The diffraction pattern was in good agreement with reported data (JCPDS No. 80-0512) for $\mathrm{BaSO}_{4}$ in orthorhombic barite phase (Salah et al 2009). $\mathrm{PL}$ emission of $\mathrm{U}^{6+}: \mathrm{BaSO}_{4}$ with $\lambda_{\mathrm{ex}}=260 \mathrm{~nm}$ consisted of an intense signal peaking around $518 \mathrm{~nm}$ with overlapping vibronic structure (figure 2). This signal was de-convoluted and resolved into five bands positioned at $498 \cdot 4,516 \cdot 0,533 \cdot 7,554.0$ and $575.1 \mathrm{~nm}$. The band at $498.4 \mathrm{~nm}$ was attributed to zero phonon transitions from first excited level of triplet ${ }^{3} \Pi_{\mathrm{u}}$ to the ground state ${ }^{1} \Sigma_{\mathrm{g}}^{1}$ of $\mathrm{UO}_{2}^{2+}$, while other bands are associated with transition from excited state to various higher vibronic levels in ground state (Ozvoldova and Bohun 1980; Wang et al 2008a). The vibronic frequency of $\mathrm{O}=\mathrm{U}=\mathrm{O}$ stretching obtained from difference in the position of successive emission bands was found to be $674 \mathrm{~cm}^{-1}$. Thus, the green emission observed in fresh and stored $\mathrm{U}^{6+}: \mathrm{BaSO}_{4}$ samples was attributed to $\mathrm{UO}_{2}^{2+}$. The stretching frequency of $\mathrm{UO}_{2}^{2+}$ in $\mathrm{BaSO}_{4}$ host is quite less as compared to that observed $\left(802 \mathrm{~cm}^{-1}\right)$ in $\mathrm{UO}_{2} \mathrm{SO}_{4}$ solid (Wang et al 2008b). In uranyl compounds, stretching frequency $\left(v_{1}\right)$ of uranyl ion was reported to be inversely proportional to the strength of interaction energy of $\mathrm{U}(\mathrm{VI})$ with co-coordinating ligands in equatorial plane. The stronger interaction between $\mathrm{U}(\mathrm{VI})$ and the equatorial ligands would result in weaker apical $\mathrm{U}=\mathrm{O}$ bond leading to lower stretching frequency (Wang et al 2004). Hexavalent uranium incorporated in solids can be present either as $\mathrm{UO}_{2}^{2+}, \mathrm{UO}_{6}^{6-}$ or $\mathrm{UO}_{4}^{2-}$ species (De Hair and Blasse 1976; E. 't Lam and Blasse 1980) and can be distinguished from their PL emission. In $\mathrm{U}^{6+}$ doped $\mathrm{CaSO}_{4}(870 \mathrm{~K}$ annealed samples), green emission of $\mathrm{UO}_{2}^{2+}$ was reported, which on annealing at $1170 \mathrm{~K}$ shifted to red region $(660 \mathrm{~nm})$ with concomitant decrease in green emission. This was attributed to formation of local uranate $\left(\mathrm{CaUO}_{4}\right)$ structure in the host

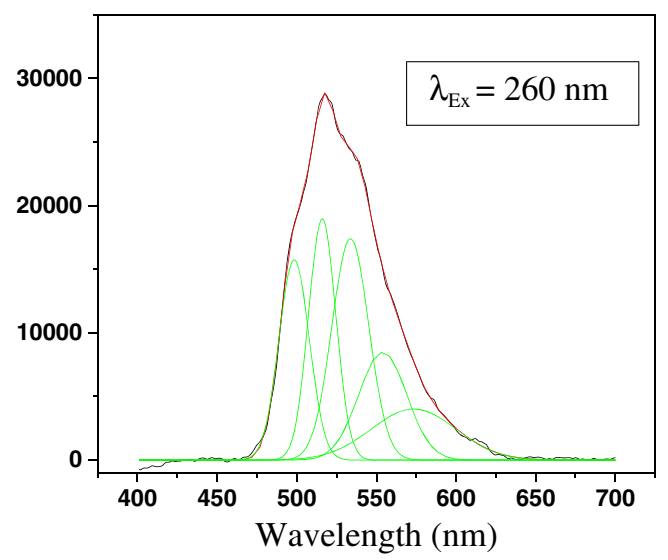

Figure 2. $\mathrm{PL}$ spectrum of $\mathrm{U}^{6+}: \mathrm{BaSO}_{4}$.

(Dalvi et al 1984). In our studies, such red shift was not observed in $1170 \mathrm{~K}$ annealed $\mathrm{U}^{6+}: \mathrm{BaSO}_{4}$ samples ruling out any possibility of $\mathrm{UO}_{4}^{2-}$ stabilization. PL spectra of $\mathrm{UO}_{4}^{2-}$ with tetrahedral structure has $\mathrm{PL}$ emission in orange-red region, while that of $\mathrm{UO}_{6}^{6-}$ (octahedral) and $\mathrm{UO}_{2}^{2+}$ species were reported in green region. However, $\mathrm{UO}_{6}^{6-}$ emission is different from that of $\mathrm{UO}_{2}^{2+}$, where the number of vibronics is smaller and the progression is much more pronounced (De Hair and Blasse 1976; Lupei and Lupei 1979). The characteristic emission of $\mathrm{UO}_{2}^{2+}$ in green region is used in structural characterization of minerals and contaminated sediments (Geipel et al 2000; Wang et al 2005). The lifetime study carried out by following decay of $518 \mathrm{~nm}$ emission had shown a single lifetime $\left(\tau_{1}=43 \mu \mathrm{s}\right)$ for $\mathrm{UO}_{2}^{2+}$ in unirradiated samples. Lifetime decreased marginally $\left(\tau_{1}=42.0 \mu \mathrm{s}\right)$ in $\gamma$ irradiated samples. This indicated only a single type of coordination around uranium in unirradiated and $\gamma$ irradiated samples.

\subsection{TSL studies}

In TSL studies reported for $\mathrm{U}$ doped $\mathrm{CaSO}_{4} / \mathrm{SrSO}_{4}$, the low doping concentration of $\mathrm{U}(0.1 \%)$ was recommended (Kumar et al 1988; Seshagiri et al 1989) for optimization of TSL intensity. In the present study, concentration of U doping in $\mathrm{BaSO}_{4}$ was increased to $1 \%$, with a view to observe uranium self irradiation effects in terms of radical generation. TSL of $\mathrm{U}^{6+}$ doped $\mathrm{BaSO}_{4}$ sample stored for 300 days gave a very weak and broad TSL signal suggesting that the population of defects produced by self irradiation was negligibly small. TSL of $\gamma$-irradiated (dose $=1.5 \mathrm{kGy}$ ) samples were recorded at different heating rates of $3,2,1$ and $0.5 \mathrm{~K} / \mathrm{s}$. TSL spectra obtained with heating rate, $\beta=2 \mathrm{~K} / \mathrm{s}$, are given in figure 3. It consisted of glow peaks at 411 and $488 \mathrm{~K}$ along with a shoulder at $512 \mathrm{~K}$. Trap depth was determined from the slope of the plot of $\ln \left(T_{\mathrm{m}}^{2}\right) / q$ vs $1 / T_{\mathrm{m}}$. A least square programme was employed to get best fit of the trap depth value. The trap parameters viz. trap depth and frequency factor for glow peaks at 411 and $488 \mathrm{~K}$ were found to be $(0.975 \pm 0.12) \mathrm{eV}, 1.1 \times 10^{11} \mathrm{~s}^{-1}$ 


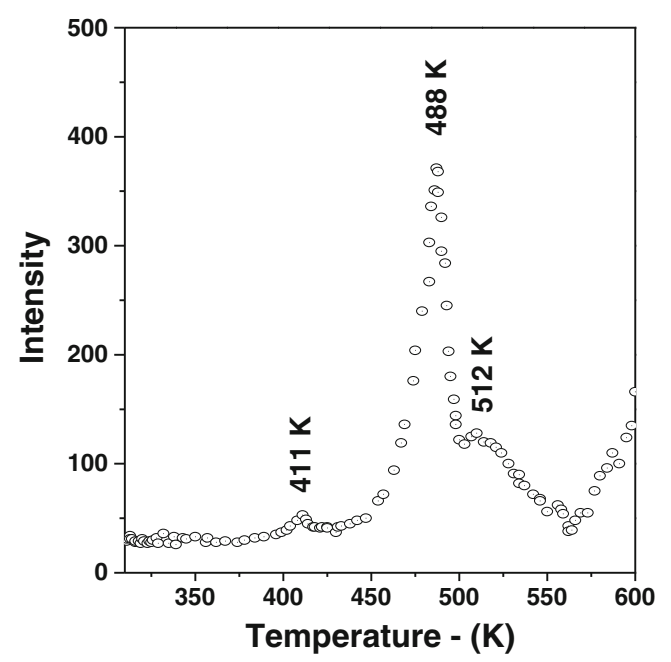

Figure 3. TSL of $\mathrm{U}^{6+}: \mathrm{BaSO}_{4}$ (heating rate $-2 \mathrm{~K} / \mathrm{s}, \gamma$-dose : $1.5 \mathrm{kGy})$ ).

and $(1.3 \pm 0.12) \mathrm{eV}$ and $4.3 \times 10^{12} \mathrm{~s}^{-1}$, respectively. For obtaining accurate trap parameters for $488 \mathrm{~K}$ peak, the $411 \mathrm{~K}$ peak was 'removed' by thermal treatment (heating to $400 \mathrm{~K}$ ). Systematic gamma dose dependence of TSL glow peaks have shown that 411 and $488 \mathrm{~K}$ peaks saturate after a gamma dose of 0.8 and $2 \mathrm{kGy}$, respectively. TSL emission spectrum in 360-650 nm was studied using narrow band interference and transmittance filters. The narrow band interference filters used had a band pass of $\pm 20 \mathrm{~nm}$. Emission observed around 480 and $520 \mathrm{~nm}$ indicated $\mathrm{UO}_{2}^{2+}$ ion to act as the emission centre.

\subsection{EPR studies}

EPR spectra of $\mathrm{U}^{6+}: \mathrm{BaSO}_{4}$ freshly prepared sample, after $\gamma$ irradiation (dose $=1.5 \mathrm{kGy}$ ) and 'stored' (300 days) due to self $\alpha$ irradiation are shown in figure 4 . EPR of self-irradiated sample generated with repetitive scans had shown a weak signal centred around $g=2 \cdot 0039$. This was attributed to $\mathrm{SO}_{3}^{-}$radical (figure 4(a)). The formation of only $\mathrm{SO}_{4}^{-}$and $\mathrm{SO}_{3}^{-}$radicals by self $\alpha$ irradiation effects was reported earlier in $\mathrm{Pu}$-doped $\mathrm{SrSO}_{4}$ (Seshagiri et al 1988) and the yield of $\mathrm{SO}_{3}^{-}$was reported to be substantially higher than that of $\mathrm{SO}_{4}^{-}$radical. The observation of very weak $\mathrm{SO}_{3}^{-}$signal in self irradiated $\mathrm{U}$ doped $\mathrm{BaSO}_{4}$ is probably due to its low specific activity as compared to ${ }^{239} \mathrm{Pu}$. EPR spectrum of $\gamma$ irradiated sample (dose $=1.5 \mathrm{kGy}$ ) consisted of signals from different radicals (figure 4(b)). These radicals were identified by comparing their $g$ values with the reported ones for $\gamma$-irradiated alkaline-earth suphates (Seshagiri et al 1988). The radical signal having axial symmetry with $g_{/ /}=2.0328$ and $g_{\perp}=2.0074$ was attributed to $\mathrm{SO}_{4}^{-}$. The signal having orthorhombic symmetry with $g_{1}=2.0039, g_{2}=2.0027$, and $g_{3}=2.0015$ and its average $g$ value $\left(g_{\text {av }}\right)$ was found to be $-g_{\mathrm{av}}=2 \cdot 0027$. This signal was identified as due to $\mathrm{SO}_{3}^{-}$and the one with $g=1.9963$ was due to $\mathrm{SH}^{2-}$ radical,

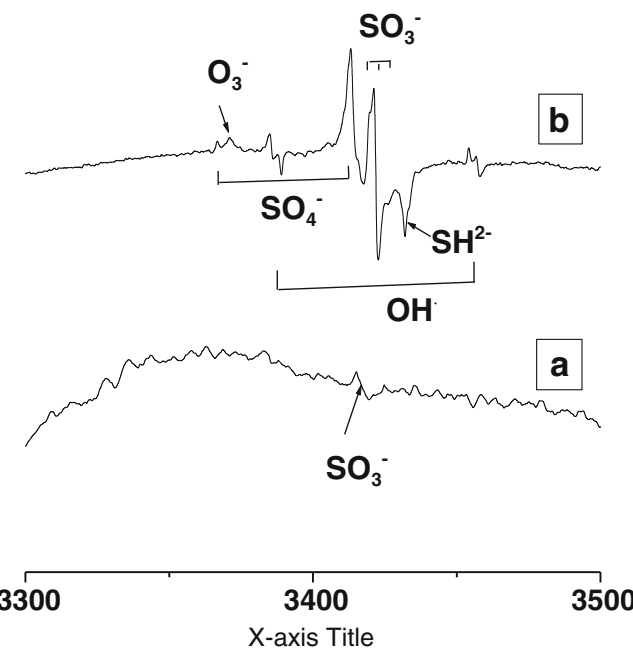

Figure 4. EPR of self irradiated (a) and $\gamma$ irradiated (b) ${ }^{\mathrm{U}} \mathrm{U}^{6+}: \mathrm{BaSO}_{4}$ samples.

respectively (figure 4(b)). A broad signal around $g=2.0353$ was attributed to $\mathrm{O}_{3}^{-}$and a set of doublet centred around $g=2.0028$ with hyperfine splitting $A=69 \mathrm{G}$ was attributed to $\mathrm{OH}^{\bullet}$ radical. In present study, signals of $\mathrm{UO}_{2}^{+}\left(5 f^{1}\right)$ were not observed down to $77 \mathrm{~K}$ with a field sweep of $12 \mathrm{kG}$. However, reduction of $\mathrm{U}^{6+}$ to $\mathrm{U}^{5+}$ is well documented in $\gamma$ irradiated alkali halides (Lupei et al 1976) and $77 \mathrm{~K}$ EPR spectrum of these samples showed $\mathrm{U}^{5+}$ signals in the field range $(15-20 \mathrm{kG})$. Thus, the formation of $\mathrm{UO}_{2}^{+}$in $\gamma$ irradiated $\mathrm{U}^{6+}: \mathrm{BaSO}_{4}$ cannot be ruled out. The stability of radiation induced radicals was monitored in the temperature range of 298-474 $\mathrm{K}$ and changes in signal intensity are shown in figure 5. $\gamma$-irradiated $\mathrm{BaSO}_{4}: \mathrm{U}^{6+}$ samples were heated using the pulsed thermal annealing technique, wherein sample was heated at desired temperature for $3 \mathrm{~min}$, followed by rapid cooling to room temperature and EPR of cooled samples was recorded at room temperature. The temperature dependence of radical signal intensity suggested that thermal destruction of $\mathrm{SH}^{2-}, \mathrm{O}_{3}^{-}$and $\mathrm{SO}_{4}^{-}$radicals occurs around $424 \mathrm{~K}$. The destruction of $\mathrm{SO}_{4}^{-}$in $\mathrm{BaSO}_{4}$ host is analogous to that reported in $\mathrm{U}$ doped $\mathrm{CaSO}_{4} / \mathrm{SrSO}_{4}$ in the range 410-440 K (Seshagiri et al 1993).

Based on TSL, PL and EPR observations, the following reaction mechanism are proposed for glow peaks.

On gamma irradiation:

$$
\begin{aligned}
& \mathrm{SO}_{4}^{2-}+h \rightarrow \mathrm{SO}_{4}^{-}+e^{-} \\
& \mathrm{UO}_{2}^{2+}+e^{-} \rightarrow \mathrm{UO}_{2}^{+} .
\end{aligned}
$$

$411 \mathrm{~K}$ peak:

On heating at $400-425 \mathrm{~K}$,

$$
\begin{gathered}
\mathrm{SO}_{4}^{-}+e^{-} \rightarrow \mathrm{SO}_{4}^{2-} \\
\mathrm{SO}_{4}^{2-} \rightarrow \mathrm{SO}_{3}^{-}+\mathrm{O}^{-} \\
\mathrm{SH}^{2-}+\mathrm{O}_{3}^{-} \rightarrow \mathrm{SO}_{3}^{-}+\mathrm{H}^{-}+e^{-} \\
\mathrm{UO}_{2}^{+}+h \rightarrow\left(\mathrm{UO}_{2}^{2+}\right)^{*} \rightarrow \mathrm{UO}_{2}^{2+}+h v
\end{gathered}
$$



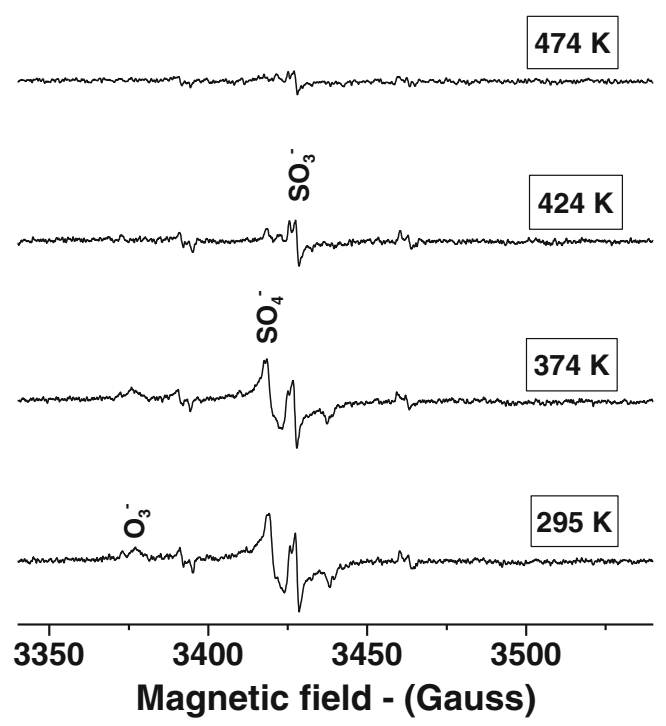

Figure 5. Temperature dependence of EPR of (a) $\gamma$ irradiated and (b) ${ }^{\mathrm{U}} \mathrm{U}^{6+}: \mathrm{BaSO}_{4}$ samples.

Also, the intensity of $\mathrm{SO}_{3}^{-}$and $\mathrm{OH}^{\bullet}$ radicals decreased significantly in $474 \mathrm{~K}$ annealed samples. This indicates that $488 \mathrm{~K}$ peak observed in TSL is related to $\mathrm{SO}_{3}^{-}$radical destruction.

488 K peak:

On heating at $470-480 \mathrm{~K}$,

$$
\begin{gathered}
\mathrm{SO}_{3}^{-}+\mathrm{e}^{-} \rightarrow\left(\mathrm{SO}_{3}^{2-}\right) * \rightarrow \mathrm{SO}_{3}^{2-}+h v, \\
\mathrm{SO}_{3}^{-}+\mathrm{O}^{-} \rightarrow \mathrm{SO}_{4}^{2-}, \\
\mathrm{OH}^{\bullet}+h \rightarrow \mathrm{OH}^{0}, \\
\mathrm{UO}_{2}^{2+}+h v \rightarrow\left(\mathrm{UO}_{2}^{2+}\right)^{*} \rightarrow \mathrm{UO}_{2}^{2+}+h v .
\end{gathered}
$$

EPR arises from the static nature of the traps while TSL occurs when electron/hole traps are ejected from charge centres. EPR experimental evidence suggested that the formation and stabilization of different radical ions in doped alkaline-earth sulphates were found to be both matrix and dopant dependent (De Hair et al 1976; E. 't Lam and Blasse 1980; Schreiber et al 1982; Dalvi et al 1984; Weast 1984; Natarajan et al 1989). In the present study, emission in the green region in $\mathrm{U}^{6+}: \mathrm{BaSO}_{4}$ was identified as due to $\mathrm{UO}_{2}^{2+}$. The thermal destruction of $\mathrm{SO}_{4}^{-}$and associated hole trapping at uranyl site was found to be responsible for TSL glow peak around $411 \mathrm{~K}$. Further, the destruction of $\mathrm{SO}_{3}^{-}$around $474 \mathrm{~K}$ was attributed to 488 TSL peak. The activation energy associated with $\mathrm{SO}_{4}^{-}$traps is in agreement with the value of $0.95 \pm 0.15 \mathrm{eV}$ reported in $\mathrm{CaSO}_{4}$ and $\mathrm{SrSO}_{4}$ host with different dopants (Seshagiri et al 1989) and supports the proposition that the trap depth values are essentially independent of dopant incorporated in the alkaline-earth sulphate matrices and are typical of binding energy of 'hole' in $\mathrm{SO}_{4}^{-}$radical.

\section{Conclusions}

Photoluminescence studies on $\mathrm{U}$ doped $\mathrm{BaSO}_{4}$ showed a typical emission of $\mathrm{UO}_{2}^{2+}$ consisting of five vibronic bands having a frequency of $674 \mathrm{~cm}^{-1}$ due to symmetric stretching of $\mathrm{O}=\mathrm{U}=\mathrm{O}$ in the ground electronic state. Self irradiation effects were found to be negligible in stored $\mathrm{U}^{6+}: \mathrm{BaSO}_{4}$. Thermal stabilities of $\mathrm{SO}_{4}^{-}, \mathrm{SO}_{3}^{-}, \mathrm{O}_{3}^{-}$and $\mathrm{SH}^{2-}$ radicals were different than those observed in $\mathrm{SrSO}_{4} / \mathrm{CaSO}_{4}$ suggesting the role of matrix and dopant in stabilization of radicals. The thermal destruction of $\mathrm{SO}_{4}^{-}$and hole trapping at $\mathrm{UO}_{2}^{+}$were found to be responsible for TSL peak observed at $411 \mathrm{~K}$ while $488 \mathrm{~K}$ peak was associated with destruction of $\mathrm{SO}_{3}^{-}$.

\section{Acknowledgements}

The authors are thankful to Dr A Goswami, Radiochemistry Division, Bhabha Atomic Research Centre, Mumbai, for his keen interest and encouragement during the course of this work.

\section{References}

Dalvi A G I, Sastry M D, Seshagiri T K and Joshi B D 1984 J. Phys. C: Solid State Phys. 175865

De Hair J, The W and Blasse G 1976 J. Lumn. 14307

E. 't Lam R U and Blasse G 1980 J. Chem. Phys. 721803

Geipel G, Bernhard G, Rutsch M, Brendler V and Nitsche H 2000 Radiochim. Acta $\mathbf{8 8} 757$

Lupei A and Lupei V 1979 J. Phys. C: Solid State Phys. 121123

Lupei S V, Lupei A, Georgescu S and Ursu I 1976 J. Phys. C: Solid State Phys. 92619

Mithlesh Kumar, Dalvi A G I and Sastry M D 1988 J. Phys. C: Solid State Phys. 215293

Natarajan V, Dalvi A G I and Sastry M D 1989 J. Phys. C: Solid State Phys. 215913

Ozvoldova M and Bohun A 1980 Czech. J. Phys. B30 1054

Salah N, Habib N S S, Khan Z H, Al-Hamedi S and Lochab S P 2009 J. Lumin. 129192

Schreiber H D and Blazs G B 1982 Phys. Chem. Glasses 23139

Schreiber H D, Blazs G B, Jamison P L and Shaffer A P 1982 Phys. Chem. Glasses 23147

Seshagiri T K, Dalvi A G I and Sastry M D 1988 J. Phys. C: Solid State Phys. 215891

Seshagiri T K, Natarajan V, Dalvi A G I and Sastry M D 1989 J. Phys. 33685

Seshagiri T K, Natarajan V and Sastry M D 1993 Nucl. Tracks Radiat. Meas. 21271

Shinde S S et al 1996 Radiat. Prot. Dosimetry 65:1-4 305

Vohra K G et al 1980 Health Phys. 38-2 193

Wang Z, Zachara J, Yantasee W A, Gassman P, Liu C and Joly A 2004 Environ. Sci. Technol. 385591

Wang Z, Zachara J M, Gassman P L, Liu C, Qafoku O and Catalano J G 2005 Geochim. Cosmo Chim. Acta 691391

Wang Z, Zachara J M, Li C, Gassman P L, Felmy A R and Clark S B 2008a Radiochim. Acta 96591

Wang Guangjun, Yi Su and Monts David L 2008b J. Phys. Chem. A 11210502

Weast R C (ed) 1984 CRC handbook of chemistry and physics (Boca Raton, FL: Chemical Rubber) 